\title{
O progresso a vapor: navegação e desenvolvimento na Amazônia do século XIX
}

Vitor Marcos Gregório Mestre em História Social pela Universidade de São Paulo

\begin{abstract}
Palauras-chave
Amazonas, navegação a vapor, Brasil Império, Parlamento, Grão-Pará.
\end{abstract}

\section{Classificação JEL N76; N96.}

Key words

Amazonas, Steam Navigation, Brazil Empire, Parliament, Grão-Pará.

JEL Classification N76; N96.

\section{Resumo}

O estabelecimento de linhas regulares de barcos a vapor na região amazônica não foi uma decisão rápida nem tampouco simples. Decorreu de longo processo decisório que se criou juntamente com o início da vida parlamentar brasileira, ainda em 1826, e passou por diversos avanços e retrocessos antes que a abertura do rio Amazonas a todos os países amigos atraíssem definitivamente o capital estrangeiro para a atividade, a partir de 1867. Este artigo pretende analisar este processo fundamental para a formação do Estado nacional brasileiro e para a definitiva incorporação da Amazônia ao conjunto do Império, ciente de que um fato de tal transcendência jamais poderia ser resolvido em poucos meses apenas com a boa-vontade de alguns paraenses em manterem-se unidos à Corte do Rio de Janeiro.

\section{Abstract}

The establishment of regular steamboat line in the Amazon region was neither a quick nor a simple decision. It was the result of a long decision-making process that was created along with the start of the Brazilian parliamentary life, in 1826. During its evolution, it underwent numerous advances and setbacks before the opening of the Amazon River to all friendly countries definitively began to attract foreign capital for the activity, starting in 1867. This article examines this crucial process for the formation of the Brazilian national state and the final incorporation of the Amazon into the Empire, recognizing that a fact of such importance could never be resolved in a few months only with the goodwill of some Paraenses to remain united to the Court of Rio de Janeiro. 


\section{Introdução}

Embora a região do rio Amazonas e de seus afluentes fizesse parte oficialmente do conjunto da América portuguesa, desde o século XVIII, ${ }^{1}$ foi somente durante o século XIX que ocorreu sua efetiva incorporação política e econômica ao Império brasileiro. Nesse processo, os esforços da Corte do Rio de Janeiro para que a província do Grão-Pará se unisse às demais, declarando oficialmente sua ruptura política com Portugal - o que logrou alcançar somente em $1823^{2}$-, tiveram grande importância, mas de forma alguma garantiram a essa região inserção favorável no contexto do recém-criado Estado. Sua situação de quase absoluto despovoamento, conjugada com o fato de que os principais centros políticos e econômicos do Império estavam localizados a milhares de quilômetros de Belém, a principal cidade amazônica na época, tornava necessária a formulação e a adoção de medidas que fortalecessem a influência do novo regime na região. Entre essas medidas, a introdução da navegação a vapor no rio Amazonas e nos principais afluentes surgia como uma das mais importantes, por impulsionar, simultaneamente, tanto o povoamento quanto o desenvolvimento econômico de todo o território localizado às suas margens. ${ }^{3}$
Desde o final do século XVIII, a navegação a vapor vinha conhecendo grande evolução técnica, que ocorria pari passu com sua crescente adoção em diversas regiões do planeta. Para isso, concorria o fato de que essa nova tecnologia tornava as viagens mais curtas e seguras, libertando os transportes de longa distância de determinantes naturais que obstruíam seu maior desenvolvimento, como a necessidade de ventos favoráveis para que a viagem ocorresse da forma mais breve possível. Ainda que inicialmente de custos mais elevados que sua congênere realizada a vela, a navegação a vapor acabou conquistando espaço não apenas por tornar as viagens mais curtas, mas também por suportar um volume maior de carga, com a vantagem de apresentar risco muito menor de perdas pelo caminho. Esse fato provocou uma queda proporcional no preço dos seguros e, num segundo momento - em que a demanda já estava bem maior -, dos fretes. Assim, em um curto espaço de tempo, os barcos a vapor dominavam as linhas transoceânicas mundiais, elevando as cifras do comércio internacional a números até então inéditos e multiplicando as possibilidades de negócio graças ao "encurtamento" das distâncias entre os mais longínquos pontos do planeta.
1 No ano de 1750 , um tratado assinado entre os governos de Portugal e Espanha, em Madrid, garantiu para o primeiro a posse sobre uma imensa área do continente sul-americano, dentro da qual se incluía grande parte da região amazônica, em troca da renúncia a suas pretensões no estuário do rio da Prata, ao sul. Ainda que esse contrato tenha sido modificado posteriormente (tratados de El Pardo, 1761 e de Santo Ildefonso, 1777), os princípios básicos do documento de 1750 não foram negados, e Portugal manteria sua posse sobre praticamente toda a bacia amazônica.

2 Detalhes sobre o processo de adesão do Grão-Pará à independência brasileira podem ser encontrados em Machado (2006).

3 Políticas de colonização e catequização dos indígenas também foram adotadas ao longo de todo o período, mas sempre em comunhão com o estabelecimento de linhas regulares de vapores nos principais rios da região e do incentivo às atividades agrícolas. Essas eram entendidas como o único meio efetivo de desenvolver a porção Norte do Império e de civilizar seus habitantes. 
Mas não foi somente na navegação oceânica que os barcos a vapor ganharam espaço ao longo do século XIX. Nas navegações fluviais, sua adoção também foi crescente em todo o período, mesmo que sofrendo a concorrência com a expansão das ferrovias. Ainda que a opção pelo transporte por terra possuísse inegáveis vantagens em interligar pontos de uma mesma região, tornando-se uma forma de transporte mais rápida que os barcos a vapor, estes últimos apresentavam a vantagem de poder aproveitar as vias naturais, que por vezes demandavam apenas obras de adequação e muito pouca manutenção, e de poder transportar uma quantidade de mercadorias muito maior do que suportavam as locomotivas. Desta forma, em regiões onde as linhas de ferro não tivessem conhecido um extraordinário desenvolvimento como no caso da Europa e dos Estados Unidos, por exemplo, onde as ferrovias logravam interligar praticamente todas as regiões de importância econômica a preços muito reduzidos -, os custos da navegação a vapor permaneciam proporcionalmente mais baixos, tornando sua implementação mais satisfatória (Sampaio, 2008, p. 5-45).

No Grão-Pará oitocentista, essas vantagens tornavam-se ainda mais notórias. Com um território cortado por grandes rios, entre os quais se sobressáa o Amazo- nas, e com a falta de recursos para a implementação de estradas de ferro, a adoção da navegação a vapor como um meio eficaz de incorporação da região no contexto político-econômico do Império e das trocas comerciais internacionais aparecia como uma solução óbvia tanto para os atores políticos provinciais quanto para os da Corte. Era necessário, entretanto, que todo um processo decisório se instaurasse e que vários projetos entrassem em debate para que se determinasse qual seria a melhor forma de realizar essa atividade. No centro das preocupações, o desejo de levar o desenvolvimento ao Norte do País foi uma das poucas unanimidades entre os diversos grupos em choque ao longo de todo o regime imperial.

\section{Primeiros debates acerca de um grande projeto}

Os primeiros projetos de introdução da navegação a vapor na região amazônica surgiram já nos primórdios do Império brasileiro, trazendo na sua esteira questões que acabariam por balizar as discussões acerca do tema ao longo de cinquenta anos. Neste sentido, já em 1826, surgiu um projeto, vindo de Nova York, de criação de uma companhia de navegação a vapor com o objetivo de realizar essa atividade nos rios da bacia amazônica. 
A Amazon Steam Navigation Company, de propriedade da firma Le Roy, Bayard \& Co., entregou, naquele ano, ao ministro brasileiro em Washington, Silvestre Rebello, um documento que anunciava o despacho, para o Grão-Pará, de um navio da companhia comandado por um filho de juiz da Corte Suprema dos Estados Unidos acompanhado de dois auxiliares, um dos quais fluente em língua espanhola. O objetivo dessa embarcação seria descarregar suas mercadorias no porto de Belém e seguir viagem rio acima, até os portos das demais nações confinantes. Enviado o navio, mediante contrato com o ministro Rebello, que prometia proteção para a empreitada, pretendeu seguir viagem a partir do porto de Belém carregado, o que ia contra a política de clausura do rio Amazonas utilizada pelo governo imperial, a exemplo do que já ocorria antes da ruptura política com Portugal. Como acabou sendo impedido de seguir viagem, a companhia processou o governo brasileiro, requerendo uma indenização pelos prejuízos sofridos com a empreitada, uma vez que o ministro Rebello teria concordado com o projeto quando comunicado de suas intenções em Washington. A indenização acabou sendo concedida, mas apenas em 1845, muitos anos após a Amazon Steam Navigation Company ter decretado falência (na realidade, já em seu retorno aos Estados Unidos, o navio enviado a Belém encontraria a companhia em situação financeira desesperadora) (Medeiros, 1938. p. 36-37).

No recém-criado Parlamento brasileiro, o acontecimento foi motivo de debates, como se tornaria comum ao longo de todo o período imperial. O contrato assinado pelo ministro brasileiro em Washington acabou sendo rejeitado, fazendo prevalecer uma ideia que permaneceria por muito tempo no tocante à questão da navegação na bacia amazônica. Segundo essa concepção, a navegação a vapor era defendida unanimemente como algo positivo para a região norte do País, desde que praticada sem interferência de capitais estrangeiros, entendidos como prejudiciais a interesses estratégicos brasileiros. Estes diziam respeito à manutenção da soberania brasileira sobre a Amazônia, território de grande potencial econômico, que, por isso mesmo, despertava a cobiça das principais potências da época (Reis, 1972).

A questão esteve longe de se encerrar em 1826. Dois anos depois, nova tentativa de introdução da navegação a vapor nos rios Amazonas, Tocantins, Solimões e Arinos foi realizada, com a fundação da Sociedade Promotora da Agricultura, Colonização, Construção de Embarcações, Comissões, Indús- 
tria Paraense na cidade de Belém. Dispondo de capitais mistos brasileiros e estrangeiros, a sociedade chegou a conseguir, em $1^{\circ}$ de fevereiro de 1834 , mediante tratativas com o governo imperial, um privilégio exclusivo de dez anos para a navegação dos rios localizados não apenas na província do GrãoPará, mas também do Maranhão (Medeiros, 2006, p. 55). Entretanto, na lógica do sistema representativo vigente no período imperial brasileiro, um privilégio desse tipo precisava ser aprovado pelo Parlamento antes de entrar em prática, razão pela qual entrou em discussão, na Câmara dos Deputados, na sessão de 6 de maio de 1834.

Nessas discussões, as ideias novamente gravitaram entre os dois polos já apresentados. Assim, para o grupo de deputados liderado por Antônio Pedro da Costa Ferreira, representante do Maranhão, e por Evaristo Ferreira da Veiga, eleito por Minas Gerais, o projeto de navegação apresentado pela companhia seria de inegável utilidade não apenas para a região amazônica, mas para todo o País, por levar o progresso a toda uma grande área que até então o desconhecia. Por outro lado, os deputados liderados por Antônio Correa Seara, representante da província do Grão-Pará, e por Antônio Peregrino Maciel Monteiro, deputado por Pernambuco, colocavam-se contra essa ideia, apontando para o fato de que a companhia em questão era formada predominantemente por capitais estrangeiros, o que criava um risco de invasão que deveria ser evitado a todo custo (Anais da Câmara dos Deputados, sessão de 22 de julho de 1834, p. 132-134). Em razão desse risco, Seara afirmou que "os paraenses" eram contrários às pretensões de Joaquim José Siqueira, representante da Sociedade, por esse ser, na realidade, um mero "testa de ferro" dos interesses ingleses na região amazônica, no que foi coadjuvado pelo requerimento de um cidadão daquela província, contrário ao privilégio em discussão. Para justificar sua oposição, afirmou Seara:

Convém, senhores, dizer que a ilha de $M a-$ rajó [ponto compreendido na área de concessão da Sociedade] é a chave da provincia do Grão-Pará, e a justiça mais rigorosa exige que ela não seja facultada a estrangeiros. Outros muitos lugares existem devoIutos naquela provincia em que há vegetais preciosíssimos, que têm desafiado a muito a ambição de tais pretendentes, e sem dúvida será a esses lugares exclusivamente que se limitarão as compras de terras, portanto toda a circunspecção neste negócio é necessária. (Anais da Câmara dos Deputados, sessão de 23 de julho de 1834, p. 135)

Mesmo com a afirmação de Ferreira da Veiga de que esse risco de invasão era inexistente, uma vez que os 
colonos a pouco e pouco iam abraçando os interesses da nação, e não havia de ser de semelhante maneira que os estrangeiros se haviam de apoderar de nossa terra (Anais da Câmara dos Deputados, sessão de 22 de julho de 1834, p. 134),

o projeto não foi aprovado nessa ocasião, sendo sua discussão adiada. Como não foram mais encontradas referências a tal discussão nas sessões subsequentes, e a sociedade nunca chegou a realizar a atividade a que se propôs - ainda que esforços para a atração de mais capitais tenham sido realizados na Inglaterra (Discurso recitado pelo Exmo. Sr. Doutor João Antônio de Miranda, presidente da província do Pará, na abertura da Assembleia Legislativa Provincial, no dia 15 de agosto de 1840, p. 78) -, é razoável supor que novamente a aprovação de um contrato previamente assinado com o governo imperial não foi alcançada no Parlamento.

Em 1837, foi tentada a formação de uma companhia de navegação de capital misto para atuar na região amazônica mais uma vez. Nesse ano, João Diogo Sturz e outros acionistas enviaram de Londres uma correspondência ao presidente da província do Grão-Pará, Francisco José Soares de Andréa, solicitando auxílio do governo provincial para formação da companhia e sua aprovação pelo governo central. Andréa não somente anuiu ao pedido, como buscou nas províncias vizinhas acionistas que pudessem fazer parte da empresa, no que não conseguiu maiores êxitos (Discurso com que o presidente da província do Pará fez a abertura da $1^{\text {a }}$ Sessão da Assembleia Provincial no dia 2 de março de 1838, p. 33). Mesmo com o fracasso em reunir maiores capitais brasileiros, Sturz levou em frente seu projeto, e um requerimento seu para realização da navegação a vapor nos rios Amazonas, Tocantins, Solimões e Negro chegou à Câmara dos Deputados, na sessão de 2 de junho de 1840 (Anais da Câmara dos Deputados, sessão de 2 de junho de 1840, p. 567).

Segundo o projeto apresentado, o grupo de empresários capitaneado por Sturz se comprometia a fundar uma companhia para introdução de linhas regulares de vapores nos rios mencionados, mediante uma série de vantagens, entre as quais as principais eram um privilégio de exclusividade para realização da atividade durante um prazo de quarenta anos, e a doação de todas as minas de carvão ou qualquer outro mineral que fossem descobertos nos primeiros anos de atividade. Além disso, a companhia receberia isenção de impostos de importação sobre quaisquer compras realizadas fora do País para manutenção da atividade - inclusive dos vapores e das fer- 
"

4 "Nasceu na Prússia em

1800, [João Diogo Sturz]

naturalizou-se brasileiro e

exerceu intensa atividade

empresarial no País. Autor de

alguns textos sobre a

introdução de máquinas no

Brasil e sobre a economia

nacional, foi um dos sócios da

Sociedade Auxiliadora da

Indústria Nacional, nas

décadas de 1830 e 1840 , e do

Instituto Histórico e

Geográfico Brasileiro,

chegando a ser nomeado, por

essa época, cônsul-geral do

Brasil na Prússia e comissário

do Império na exposição geral

da indústria realizada em

Londres, em 1851" (Gregório, 2008, p. 27-28). ramentas necessárias para sua manutenção - e a doação de dez sesmarias de terras devolutas com uma milha quadrada cada, com a condição de que essas fossem utilizadas para a criação de colônias de europeus na Amazônia (Anais da Câmara dos Deputados, sessão de 2 de junho de 1840 , p. 567-568).

$\mathrm{Na}$ discussão ponto a ponto dos artigos constantes do documento, prevaleceu a ideia segundo a qual a introdução da navegação a vapor e de colônias estrangeiras na região Norte seria extremamente benéfica para o País. Para que esse objetivo fosse alcançado, entretanto, fazia-se necessária a concessão de vantagens extraordinárias aos empresários que se dispusessem a realizar tal empresa, como a concessão de um privilégio de exclusividade tão longo como o previsto pelo projeto. Mas essa posição não foi aceita sem debates. Nesse sentido, formaram-se dois grupos de deputados, os favoráveis às vantagens concedidas, e os contrários a elas. Venâncio Henriques de Rezende, deputado por Pernambuco, liderou o grupo dos opositores, defendendo $\mathrm{o}$ argumento segundo o qual um privilégio de quarenta anos não era tão necessário para a realização da navegação a vapor, na realidade era mesmo excessivo, uma vez que, no rio Amazonas, não seria necessária obra alguma para tornar possível a atividade que se pretendia introduzir. Assim, se, pois, à vista destas considerações acha [va] excessivo o privilégio de 40 anos, muito mais excessivo acha [va] a isenção dos direitos de todos os utensílios e máquinas que a companhia importar pelo prazo de 10 anos (Anais da Câmara dos Deputados, sessão de 27 de julho de 1840 , p. 370).

A ideia dos opositores do projeto era bastante clara. Por um lado, temia-se que a companhia intentada por Sturz fosse apenas uma fachada para que o grupo de empresários que ele liderava especulasse com o privilégio concedido, repassando-o a preços altos tão logo fosse concedido pelo governo. Se isso ocorresse, seriam atendidos apenas os seus interesses particulares em prejuízo das necessidades da Nação, o que de forma alguma poderia ser aceito pelos deputados (Anais da Câmara dos Deputados, sessão de 27 de julho de 1840, p. 371). Pior que isso, era o fato de que um dos principais propugnadores do projeto, Diogo Antônio Sturz, era estrangeiro, ${ }^{4} \mathrm{o}$ que alimentava o temor de que a companhia formada se estabelecesse em outro país qualquer, fazendo predominar interesses externos ao Império com relação ao controle de um comércio imenso e vital para o Império. Neste sentido, Henriques de Rezende pôde afirmar que

não é $[\mathrm{ra}]$ daqueles que lamenta $[v a] m$ que os estrangeiros se enrique [cessem] no Bra- 
sil: pelo contrário, estima [va] e deseja [va] que assim aconte[cesse], mas não sendo as vantagens somente para os estrangeiros, mas também para o país (Anais da Câmara dos Deputados, sessão de 27 de julho de 1840, p. 372).

Finalmente, a isenção de impostos oferecida para a compra de utensílios era entendida como uma ameaça para uma das principais fontes de renda do Império, a cobrança de tributos sobre a importação e exportação de mercadorias (Dolhnikoff, 2005, p. 156-171). Uma vez estabelecida essa vantagem, nas palavras de Joaquim Francisco Vianna, deputado pelo Rio de Janeiro,

nada há [via] mais fácil do que mandar vir grande porção de enxadas, machados, e tudo quanto se pode chamar utensíllio]s, despachar no Pará livre de direitos, e exportar para o Rio de Janeiro e outras províncias (Anais da Câmara dos Deputados, sessão de 27 de julho de 1840, p. 371).

O risco de criação de um tal contrabando acabou sendo a única das ideias contrárias ao projeto a encontrar algum eco na Câmara dos Deputados, tendo motivado a aprovação de uma emenda que buscava garantir que as máquinas e as ferramentas que teriam isenção de impostos seriam apenas aquelas necessárias para mover os vapores da companhia (Anais da Câmara dos Deputados, sessão de 27 de julho de 1840, p. 373). Os demais artigos do pro- jeto foram todos aprovados sem qualquer modificação, e esse foi rapidamente enviado ao Senado para deliberação.

Nessa instância parlamentar, mais discussão, com uma divisão maior entre os grupos. Enquanto entre os deputados era quase geral o sentimento de que o projeto trazia vantagens para o País, ao iniciar uma atividade fundamental para o desenvolvimento da região amazônica, entre os senadores havia uma grande cisão entre os que aceitavam esse argumento e os que defendiam que o projeto, ao invés de auxiliar no desenvolvimento do País, serviriam para atravancá-lo. Assim, na sessão de 22 de maio de 1841, o senador Nicolau Pereira de Campos Vergueiro leu diante à assembleia o parecer que a comissão de comércio - da qual fazia parte - elaborou acerca do projeto. Ao contrário do que ocorrera na Câmara, os termos desse parecer eram francamente opostos à proposta do grupo de empresários liderados por Diogo Sturz. Os argumentos apresentados, resumidamente, eram três. O monopólio de quarenta anos pedido pelo grupo de empresários era longo demais, e portanto não poderia ser aprovado, ao passo que os demais favores eram aceitáveis, desde que estendidos a todos os empresários interessados em realizar a navegação a vapor da região amazônica.

A oposição ao privilégio de exclusividade provinha ainda de um elemento 
mais forte. No entender da comissão, sua concessão seria inconstitucional, uma vez que essa, em seu artigo 179, parágrafo 24, garantiria o livre exercício de qualquer indústria por quaisquer brasileiros, ficando aberta uma exceção, no parágrafo 26, em favor dos inventores, que poderiam gozar dos privilégios de exclusividade sobre suas invenções por um período determinado. Assim, para os senadores membros da Comissão de Comércio, nenhuma atividade poderia ser desenvolvida sem o concurso da livre concorrência e, nesse sentido, longe de auxiliar no desenvolvimento da região Norte do País, o projeto analisado representaria um entrave a que esse objetivo fosse alcançado (Anais do Senado, sessão de 22 de maio de 1841, p. 159-160).

O debate assumiria, nas sessões seguintes, características de embate entre duas estratégias para o desenvolvimento do País completamente antagônicas. De um lado, defendida por senadores como Nicolau Pereira de Campos Vergueiro e Holanda Cavalcanti de Albuquerque, estava a ideia segundo a qual a navegação a vapor deveria ser introduzida na região amazônica mediante o estímulo da livre concorrência, e não com privilégios de exclusividade, que entendiam ser um entrave ao progresso do Brasil. Já para o grupo de senadores capitaneado por Saturnino da Costa Perei- ra, Manoel Alves Branco e Francisco Carneiro de Campos, entre outros, o privilégio de exclusividade era um mal necessário, uma vez que a atividade que pretendiam iniciar não teria sido realizada anteriormente, impossibilitando qualquer companhia que fosse empreendê-la de prever seus lucros ou prejuízos e obrigando o governo a oferecer os meios necessários para não desinteressá-la da empresa. Esse poderia ser um debate econômico clássico entre conservadores e liberais, se não existissem senadores do Partido Liberal defendendo ambas as posições em confronto.

Depois de acalorados discursos em que nenhum dos lados conseguiu demover o outro de sua posição, a questão acabou sendo adiada graças a um requerimento apresentado por Saturnino da Costa Pereira, senador defensor do projeto em discussão, na sessão de 8 de junho de 1841. A justificativa para o adiamento foi a requisição de mais informações sobre o assunto ao governo, para que os senadores pudessem continuar a discussão com dados mais precisos (Anais do Senado, sessão de 8 de junho de 1841, p. 140). Essas informações, entretanto, nunca chegariam ao Senado, e o projeto só foi retomado em 19 de janeiro de 1864, após quase vinte e três anos, apenas para ser rapidamente rejeitado em votação desprovida de quaisquer discursos 
(Anais do Senado, sessão de 25 de janeiro de 1864 , p. 80). Ainda não seria dessa vez que o rio Amazonas teria suas águas navegadas por linhas regulares de barcos movidos a vapor.

\section{Criação da Companhia de Navegação e Comércio do Rio Amazonas e contrato com o governo imperial}

A questão da navegação a vapor na região amazônica ganhou novos contornos no início da década de 1850, com o aumento das pressões internacionais pela abertura do rio Amazonas aos barcos de todas as nações. As cobranças maiores vinham dos Estados Unidos, onde o tenente da Marinha Mathew Fontaine Maury iniciara uma grande campanha com o objetivo de conseguir para seu país o direito de navegar as águas daquele rio. De conversas informais e formais com membros do governo estadunidense, e de uma grande campanha na imprensa, que culminaria com a publicação do livro $O$ Amazonas e as costas atlanticas da América meridional (Maury, 1853) - no qual narra grandes riquezas e um enorme potencial de lucro existente na região amazônica -, Maury conseguiu que surgissem pedidos formais do governo daquele país que levaram a admi- nistração imperial a tomar a questão sob um ângulo de urgência até então inédito. ${ }^{5}$

Essa situação explica, em parte, a aceleração do processo de criação da província do Amazonas, ${ }^{6}$ mediante a aprovação da Lei n. 582, de 5 de setembro de 1850, e a elaboração da Lei n. 586, de 6 de setembro de 1850, que autorizavam o governo imperial a contratar a navegação a vapor do rio Amazonas mediante oferta de subvenções pecuniárias. $\mathrm{O}$ informe reservado escrito pelo ministro brasileiro na le-

$\begin{array}{ll}\text { 5 Sobre a questão envolvendo } & \text { informações sobre o assunto, } \\ \text { os governos estadunidense e } & \text { o que nunca ocorreu. Em 1839, } \\ \text { brasileiro no tocante à } & \text { novo projeto foi apresentado } \\ \text { navegação do rio Amazonas, } & \text { por outro deputado do } \\ \text { ver Medeiros (1938). } & \text { Grão-Pará, João Cândido de } \\ 6 \text { Os debates acerca da elevação } & \begin{array}{l}\text { Deus e Silva. Esse entrou em } \\ \text { debate em 1840, tendo sido }\end{array} \\ \text { da província do Alto Amazonas, } & \text { aprovado na Câmara e remetido } \\ \text { depois Rio Negro, à categoria de } & \text { para o Senado, apenas em junho } \\ \text { província vinham se arrastando } & \text { de 1843. Na casa vitalícia, } \\ \text { desde 1826, quando o deputado } & \text { entretanto, o projeto mereceria } \\ \text { pelo Grão-Pará, Romualdo } & \text { consideração só em 1850, } \\ \text { Antônio de Seixas, apresentou } & \text { quando foi rapidamente } \\ \text { projeto nesse sentido. Após } & \text { aprovado. Daí se vê que, embora } \\ \text { análise e alterações realizadas } & \text { a conjuntura externa tenha } \\ \text { pela comissão de estatística da } & \text { favorecido a aprovação da } \\ \text { Câmara, o projeto entrou em } & \text { criação da província do } \\ \text { discussão na casa, apenas em } & \text { Amazonas, essa discussão vinha } \\ \text { 1828. Aprovado em primeira e } & \text { desde a criação do Parlamento } \\ \text { segunda discussões, somente em } & \text { brasileiro, sempre sob a égide da } \\ \text { 1832 seriam retomados os } & \text { necessidade de desenvolvimento } \\ \text { debates em terceira discussão. } & \text { e defesa eficientes da região } \\ \text { Nessa ocasião, aprovou-se a } & \text { Norte do Império (Gregório, } \\ \text { suspensão dos debates para que } & \text { 2008, p. 281-295). } \\ \text { o governo remetesse novas } & \end{array}$


(1)

Teixeira de Macedo para

Paulino Soares de Souza, ministro dos Negócios

Estrangeiros, 14 de novembro de 1850 apud Reis

(1982, p. 60) gação de Washington, Teixeira de Macedo, e remetido ao ministro dos Negócios Estrangeiros, visconde do Uruguai, em 14 de novembro de 1850 , deu concretude aos temores brasileiros. Nesse documento, Macedo narrava as conversas reservadas que havia tido com membros influentes do governo estadunidense, e a imensa campanha que se desenrolava na imprensa daquele país, sempre no sentido de conseguir, à força se necessário fosse, a abertura da navegação do rio Amazonas. Para resistir a essas pressões, tornava-se necessário desenvolver e tornar a presença do governo brasileiro mais efetiva em toda a região. Neste sentido, aconselhava o ministro:

Eu entendo que a boa economia política quer que as indústrias, que possam ser exercidas pelos brasileiros sem auxílio estranho, lhe sejam exclusivamente reservadas pelos meios conhecidos e indiretos, de tarifas protetoras e outras; que as indústrias que não podem nascer sem o auxílio de privilégios exclusivos, de isenções, de prêmios e outras animações diretas do Governo, se forem vantajosas, obtenham esses incitamentos; e aquelas enfim que só podem nascer da livre concorrência nacional e estrangeira sejam a essa concorrência abandonadas.

[...] Neste último caso entendo achar-se a navegação do Amazonas. ${ }^{7}$
A postura a ser adotada deveria ser pragmática. A análise circunstanciada da questão em foco é que deveria definir qual a política a ser adotada com relação à navegação a vapor do rio Amazonas. Teixeira de Macedo entendia que o melhor para desenvolver essa atividade seria a incitação de uma concorrência direta entre os capitais nacionais e os estrangeiros interessados em levá-la adiante. Não havia, entretanto, na administração imperial - entendida como a conjunção dos Poderes Executivo, Legislativo, Judiciário e Moderador -, inclinação alguma a adotar essa prática, como ficou demonstrado em todas as ocasiões que o tema foi a debate, desde 1826. A solução adotada, então, foi a assinatura de um contrato entre o governo imperial e Irineu Evangelista de Souza, futuro barão de Mauá, para introdução, com capitais puramente nacionais, da navegação a vapor no rio Amazonas, em 1852.

De acordo com esse contrato, oficializado pelo Decreto n. 1.037, de 30 de agosto de 1852, estava prevista a concessão, por parte do governo, de uma subvenção pecuniária mensal, que seria acrescida de um privilégio de exclusividade na realização da empresa que deveria vigorar pelos próximos trinta anos. Além disso, seria realizada a cessão de terras para a fundação de sessenta colônias nas margens do rio, a se- 
rem habitadas por indígenas ou imigrantes estrangeiros, além de um terreno no qual deveria ser construído um dique na cidade de Belém. Em contrapartida, Irineu Evangelista de Souza se comprometia a fundar uma companhia que nunca operasse com capital inferior a mil e duzentos contos de réis, que mantivesse linhas regulares de vapores e que se comprometesse a fundar e a manter as colônias nas margens do Amazonas, tão logo obtivesse do Poder Legislativo autorização para isso (Anais da Câmara dos Deputados, sessão de 11 de julho de 1853 , p. 152-153). Sobre essas bases, foram inauguradas as primeiras linhas regulares de vapores do rio Amazonas, em janeiro de 1853, mantidas pela Companhia de Navegação e Comércio do Rio Amazonas.

Pela lógica do sistema representativo imperial, contudo, essa medida - embora tenha pretendido se apoiar sobre a Lei n. 586, de 1850 - não poderia ser adotada sem aprovação do Poder Legislativo. E o governo imperial seria asperamente lembrado disso nos debates que se desenrolaram na Câmara dos Deputados, durante o ano de 1853 (Gregório, 2008, p. 102-112). Tanto na Câmara quanto no Senado, tornaria a prevalecer, assim como em 1840, a ideia segundo a qual a concessão de um privilégio de exclusividade para a introdução da navegação a vapor no rio Amazonas serviria como um obstáculo ao desenvolvimento da região, e não como um impulsionador, como queriam os idealizadores do contrato.

Nesse sentido, na Câmara, um grupo de deputados capitaneados por Cândido Mendes de Almeida, representante da província do Maranhão, e Ângelo Muniz da Silva Ferraz, deputado pela Bahia, esforçou-se por demonstrar os inconvenientes da concessão do privilégio de exclusividade. Segundo esses deputados, o pagamento de uma subvenção financeira à companhia de Irineu Evangelista de Souza já seria suficiente para garantir seus lucros e, portanto, seu interesse em empreender a atividade. Assim, a concessão de um privilégio de exclusividade válido por trinta anos - entendido como um período muito longo - a uma companhia com capital mínimo de mil e duzentos contos de réis - entendido como muito pequeno para a grandiosidade da empresa - seria desnecessária e temerária, já que impossibilitaria a formação de outras companhias maiores e mais bem equipadas quando a navegação começasse a dar os imensos lucros que se esperavam dela. A concorrência surgiu, assim, como algo extremamente benéfico para esses deputados, já que seria capaz de apressar o desenvolvimento do comércio na região amazônica, tornando-a, em pouco tempo, autossufici- 
ente (Anais da Câmara dos Deputados, sessão de $1^{\circ}$ de agosto de 1853 , p. 7-8).

Para agravar a situação criada pelo contrato, a navegação do trecho brasileiro do rio Amazonas acabaria ficando em uma situação de desvantagem comparativamente aos demais países ribeirinhos, o que seria inadmissível, segundo Mendes de Almeida:

O que acontecerá é que peruvianos (sic), os equatorianos, os habitantes da Nova Granada e Venezuela, todos navegarão livremente o Amaronas com proveito seu, e nós que possuimos o ponto mais importante desse rio, como é a sua embocadura, e em grande extensão e sua parte mais navegável, seremos reduzidos à navegação promovida por uma só companhia, e de tão pequenos fundos, que dirigirá a mesma navegação de conformidade com o seu interesse, com o monopólio que se lhe concede. (Anais da Câmara dos Deputados, sessão de $1^{\circ}$ de agosto de 1853 , p. 8 )

A concessão do privilégio de exclusividade tal como previsto no contrato acabaria por prejudicar uma das principais fontes de renda para o País, advindas da introdução da navegação a vapor no rio Amazonas. A ideia expressa por esse trecho do discurso de Mendes de Almeida traz em si uma concepção do papel que a bacia amazônica deveria exercer no contexto das trocas internacionais. É preciso lembrar que, antes que a inauguração do Canal do Panamá, ocorrida em 1914, tornasse as comunicações dos países andinos com a Europa mais fáceis, rápidas e baratas, a única forma possível de transporte da sua produção para os maiores mercados consumidores do mundo se dava através do Cabo Horn, ao sul do continente, em uma viagem longa e dispendiosa, que não raro acabava em acidentes e perda total da carga, dada as condições climáticas da região. Nesse contexto, o rio Amazonas e seus principais afluentes surgiam como a solução mais natural para facilitar o escoamento dessa produção, tornando as mercadorias andinas mais competitivas no mercado internacional por meio do barateamento do frete e da diminuição dos preços dos seguros.

Por outro lado, ao governo imperial e às administrações provinciais cujo território era banhado por esses rios também interessava que o comércio andino se desse pela bacia amazônica, uma vez que o pagamento dos fretes e a cobrança de eventuais pedágios durante o trajeto traziam em si um potencial de lucro até então inédito para essa região. Neste sentido, a criação de um monopólio no trecho brasileiro do rio seria inadmissível para os opositores do contrato, já que criaria um verdadeiro funil que dificultaria esse transporte, com o que 
deixariam de ganhar tanto os governos provinciais quanto o geral.

Ao argumento de que seria impossível introduzir a navegação a vapor no rio Amazonas sem a concessão do privilégio, Mendes de Almeida opôs a proposta de criação de uma companhia de capital misto estrangeiro e nacional, o que sintomaticamente nem foi debatido na Câmara. O aumento das pressões internacionais e os temores de perda da soberania brasileira sobre a região amazônica, que poderia advir de tal medida, ainda impossibilitavam a aceitação do investimento de capitais estrangeiros em atividade tão estratégica para o País (Anais da Câmara dos Deputados, sessão de 18 de agosto de 1853, p. 238-241).

Mesmo com a existência de um grupo de deputados liderado pelo representante de Mato Grosso, Viriato Bandeira Duarte, defendendo que a concessão do privilégio de exclusividade era um mal necessário, sem o qual não seria possível instituir a navegação a vapor no rio Amazonas nem a colonização das suas margens (Anais da Câmara dos Deputados, sessão de 2 de agosto de 1853 , p. 27-29), o contrato acabou sendo aprovado pela Câmara com uma emenda que previa a supressão dessa vantagem. Isso significava que o governo imperial deveria resgatá-la, do modo que julgasse mais conveniente, o quanto antes.
Nem mesmo as tentativas do ministro do Império, Francisco Gonçalves Martins, de convencer os deputados da conveniência da manutenção do privilégio surtiram efeito (Anais da Câmara dos Deputados, sessão de 18 de agosto de 1853, p. 238-241). Como no Senado essa posição foi mantida sem maior oposição, a única saída para o Poder Executivo imperial foi reformar o contrato assinado com Irineu Evangelista de Souza, cancelando a concessão do privilégio de exclusividade. $\mathrm{O}$ resultado foi o novo contrato firmado entre ambas as partes em 2 de outubro de 1854, oficializado pelo Decreto n. 1.445. Por esse novo documento, a companhia abria mão, além do privilégio, da preferência para navegação dos afluentes do rio Amazonas e para abertura de vias de comunicação lateral a esses rios - outro ponto bastante criticado nos debates da Câmara dos Deputados. Mais ainda, ficou comprometida a operar duas novas linhas além das originais e a fundar doze novas colônias além das sessenta previstas inicialmente. Em compensação, o governo oferecia setenta territórios de duas léguas quadradas cada um, além de terrenos de marinha devolutos. Desta forma, acreditava o novo ministro do Império, Luiz Pedreira do Couto Ferraz, "as intenções do poder Legislativo ficarão satisfeitas do melhor modo que era possível." (Relatório do 
.

8 Santos (1980. p. 55) - Jorge Caldeira narra, no princípio de sua obra sobre o barão de Mauá, o momento de grande prosperidade econômica de que o empresário gozava no início da década de 1860 , graças, entre outras coisas, ao sucesso conquistado por sua companhia de navegação fundada para atuar no Norte do Império (Caldeira, 1995).
Ministério do Império, 14 de maio de 1855, p. 35-37)

Ainda que o novo contrato atendesse melhor ao que o Parlamento imperial entendia serem os interesses nacionais, acabou tendo vida curta. Em 1857, após novo debate na Câmara dos Deputados e no Senado, Irineu Evangelista de Souza conseguiu que fosse cancelada a obrigatoriedade de sua companhia fundar colônias na região amazônica - tarefa que estava se mostrando dispendiosa e com poucos resultados positivos - e que fosse oferecido um aumento na subvenção paga pelo governo imperial - de trinta e um para trinta e cinco contos de réis anuais (Relatório do Ministério do Império, 6 de maio de 1858, p. 56-58). Utilizou como principal argumento os balancetes da Companhia de $\mathrm{Na}$ vegação e Comércio do Rio Amazonas que comprovavam que estava operando com prejuízo desde a assinatura do contrato de 1854, e os relatos de insucesso com relação às tentativas de fundação de colônias na região. Desta forma, o Decreto n. 1.988, de 10 de outubro de 1857, que oficializou a nova reforma do contrato, comprovou que, embora os administradores imperiais estivessem empenhados em realizar a navegação a vapor do rio Amazonas da forma mais vantajosa possível para o Império, isso não poderia ser feito sem que ficasse ga- rantida a viabilidade econômica dessa atividade. Os interesses nacionais, nesse caso, não conseguiram se impor a uma realidade econômica que se apresentava desfavorável aos investimentos.

\section{Década de 1860: debates parlamentares e abertura do rio Amazonas}

Os termos do debate acerca da navegação a vapor no rio Amazonas e de seus afluentes mudaram significativamente no início da década de 1860. A Companhia de Navegação e Comércio do Rio Amazonas estava completando uma década de atividades, e seus resultados eram bastante positivos. O número de passageiros aumentava ano a ano, bem como a quantidade de carga transportada pelos vapores da companhia. O número de linhas e de portos tocados pelas embarcações também se multiplicou, o que demonstrava o estado de prosperidade obtido pela companhia do futuro barão de Mauá, cuja renda, em 1867, era dez vezes maior do que fora em $1853 .{ }^{8}$

Para a administração imperial, os resultados alcançados pela companhia também eram satisfatórios. Os números referentes ao comércio internacional realizado pela província do Grão-Pará aumentaram 
consideravelmente desde o início da operação das linhas de vapores, em 1853, e isso não poderia deixar de ser benéfico também para o Tesouro geral (Quadro 1).

O valor das importações aumentou pouco mais de duas vezes desde a época anterior ao início das atividades da empre- sa, número inferior, entretanto, ao do aumento das exportações, que multiplicou por 3,5 desde 1851. Com isso, a renda provincial auferida com os valores relativos a importações, exportações e despachos marítimos realizados pelo porto de Belém elevou-se da cifra de 519:548\$805, no ano fis-

\section{Quadro 1_ Evolução do comércio exterior da província do Grão-Pará (em contos de réis)} 1851-1866

\begin{tabular}{|c|c|c|}
\hline Ano Fiscal & Importação & Exportação \\
\hline 1851-1852 & $2.299: 636 \$ 645$ & $1.839: 627 \$ 025$ \\
\hline $1852-1853$ & $2.866: 239 \$ 194$ & $2.596: 287 \$ 235$ \\
\hline 1853-1854 & $4.573: 656 \$ 697$ & $5.286: 916 \$ 940$ \\
\hline 1854-1855 & $3.609: 584 \$ 794$ & $3.854: 846 \$ 820$ \\
\hline 1855-1856 & $2.862: 154 \$ 007$ & $3.477: 058 \$ 500$ \\
\hline 1856-1857 & $3.616: 719 \$ 940$ & $4.055: 965 \$ 188$ \\
\hline $1857-1858$ & $3.688: 600 \$ 876$ & $3.549: 631 \$ 467$ \\
\hline 1858-1859 & $3.946: 363 \$ 957$ & $3.917: 104 \$ 528$ \\
\hline 1859-1860 & $4.709: 895 \$ 560$ & 5.912:860\$040 \\
\hline 1860-1861 & $5.704: 745 \$ 464$ & $5.341: 303 \$ 713$ \\
\hline 1861-1862 & $3.618: 976 \$ 206$ & $4.602: 299 \$ 657$ \\
\hline 1862-1863 & $4.471: 313 \$ 653$ & $5.551: 075 \$ 321$ \\
\hline 1863-1864 & $5.244: 233 \$ 585$ & $5.826: 790 \$ 623$ \\
\hline 1864-1865 & $4.566: 470 \$ 475$ & $5.840: 414 \$ 278$ \\
\hline $1865-1866$ & $4.613: 217 \$ 693$ & $6.952: 744 \$ 547$ \\
\hline
\end{tabular}

Nota: Quadro construído com os valores apresentados nos relatórios dos presidentes da província apresentados à

Assembleia Legislativa Provincial do Grão-Pará, no período citado. Os relatórios podem ser encontrados no site

$<$ http://brazil.crl.edu/bsd/bsd/hartness/minopen.html> 
9 Pasta criada em 1860 e que herdou do Ministério do Império as atribuições sobre as obras e as medidas destinadas às navegações costeira e fluvial. cal de 1849-1850, para 2.242:891\$862, em 1866-1867 (Relatório apresentado à Assembleia Legislativa Provincial na primeira sessão da $17^{\mathrm{a}}$ legislatura, pelo $4^{\circ}$ vice-presidente, doutor Abel Graça, 1870, p. 29-30), um aumento de cerca de $432 \%$ em dezessete anos. Mesmo descontadas as perdas referentes ao processo inflacionário da época e de possíveis desvalorizações cambiais, e considerando que grande parte desse aumento se deve às flutuações - extremamente favoráveis - do preço da borracha no mercado internacional (responsáveis também pela alteração brusca, para mais ou para menos, dos números provinciais de um ano para o outro), é inegável que essas cifras representavam aumento considerável na arrecadação do governo. Sem a introdução da navegação a vapor na região, certamente essas cifras não poderiam ser alcançadas.

Era necessário, entretanto, dar um passo além no processo de desenvolvimento econômico da região amazônica. Com o aumento considerável dos valores circulados pelas águas fluviais da região, a Companhia de Navegação e Comércio do Rio Amazonas, que havia sido uma das principais responsáveis pelos números alcançados até então, passava a ser encarada, juntamente com a subvenção pecuniária que recebia, como um obstáculo para seu incremento. Para os responsáveis pela ad- ministração imperial do início da década de 1860, o "funil" previsto por Mendes de Almeida estava se concretizando, e era preciso adotar medidas para evitar que ele provocasse o colapso do processo a tanto custo iniciado uma década antes. Era chegada a hora da abertura da navegação do Amazonas a todos os países.

O ministro da Agricultura, Comércio e Obras Públicas, ${ }^{9}$ Pedro de Alcântara Bellegarde, demonstrou, já em seu relatório apresentado ao Parlamento, em 1863, suas intenções de adotar medidas nesse sentido. Assim, a exploração dos rios amazônicos estaria prestes a se tornar uma realidade, como uma medida prévia à sua completa abertura às embarcações estrangeiras. Não estava exclusivamente nas mãos do Poder Executivo, entretanto, adotar essa política, como o próprio ministro demonstrou em seu relatório apresentado à Assembleia Geral em 1864:

A abertura do rio Amazonas ao comércio das nações que estão em paz com o Império, é certamente um dos fatos que o governo imperial mais deseja ver realizado, e de que espero os mais felizes resultados. Entretanto não depende somente dele, mas principalmente de medidas de competência da assembléia geral legislativa, apressar um acontecimento que tão grande influência tem de exercer nas relações comerciais 
do país, e na prosperidade das provincias ribeirinhas. (Relatório do Ministério da Agricultura, Comércio e Obras Públicas, 10 de janeiro de 1864 , p. 20$)$

Na sessão da Câmara dos Deputados de 13 de fevereiro de 1864, exatamente um dia após a morte do ministro Bellegarde, iniciaram-se os debates acerca do tema da abertura do rio Amazonas. Nos discursos que se seguiram, ficou demonstrado que a franca maioria dos deputados estava a favor da abertura, o que, entretanto, não significava que essa posição era unânime. Novamente voltariam à tona, mas agora em franca minoria, as mesmas ideias que haviam determinado as políticas adotadas com relação à região até o momento.

Nesse sentido, o deputado pela Bahia, João José de Oliveira Junqueira, formulou em termos bastante precisos seus receios quanto à abertura, na seguinte fala:

Quero que o Pará hoje e sempre continue a mandar para aqui representantes como os nobres deputados; mas receio que em futuro, que talvez não estivesse muito longe, a continuar a inangurar-se uma politica como esta, fértil nas suas conseqüências, não tivéssemos o prazer de ver os ilustrados deputados cooperando conosco para o bem do país. Desejo que o Brasil que nos foi transmitido desde o Oiapoque, desde o Amazonas até a vizinhança do Prata, seja o mesmo Brasil daqui a alguns séculos. [...]
É preciso que os que têm pensado sobre a questão cheguem aos seus corolários; esses corolários são forcosos: uma vasta região habitada por uma grande população de uma raça diferente de costumes, religião e linguas diversas, não pode facilmente fazerparte da mesma sociedade. (Anais da Câmara dos Deputados, sessão de 22 de abril de 1864, p. 249)

O temor de perda da soberania brasileira sobre a região amazônica, mais uma vez, encontrava eco no Parlamento, mas, dessa vez, sem chance de êxito. Combatido por Tavares Bastos, Tito Franco de Almeida e por Domingos Antônio Raiol, entre outros deputados, o deputado baiano encontrou-se em franca minoria, e seus argumentos foram classificados como reflexos de uma "doutrina dos preconceitos, dos receios e sustos" (Anais da Câmara dos Deputados, sessão de 11 de junho de 1864, p. 126). Para a maioria dos deputados gerais, entre os quais toda a bancada da região amazônica, tais receios não possuíam qualquer fundamento, afinal, segundo Franco de Almeida,

[...] se houvesse idéia de absorção, se tivéssemos de temer o predominio de qualquer raça estranha, não poderíamos ter hoje no Amazonas? Alguém pode proibir os estrangeiros de adquirirem terras e fortuna, de navegarem livremente como navegam no Amazonas, de transportarem todos os pro- 
dutos que adquiram? Mas porque não tem havido tal absorção? Porque não existe tal intenção nem pode existir no século XIX; porque seria irrisória... (Anais da Câmara dos Deputados, sessão de 23 de abril de 1864, p. 262)

Nesse momento, a percepção era de que a sobrevivência do País dependia, em grande medida, da boa vontade das grandes potências em garanti-la. Uma vez que esse contexto não mais existisse, ou que esses países passassem a ter o interesse de tomar posse da região amazônica, mesmo o deputado paraense aceitava a tese de que qualquer resistência tornar-se-ia impossível, e de que o processo de formação do Estado nacional, então em andamento, estaria irremediavelmente condenado. Nesse sentido, não havia por que se opor à abertura, que traria grande possibilidade de êxito na tarefa de desenvolver o Norte, sem oferta de riscos maiores ao País. Se essa medida trouxesse alguma mudança significativa nas relações externas no Império, seria apenas no sentido de melhorá-las, já que possibilitaria maior apoio internacional às pretensões brasileiras, já bastante prejudicadas pela política de clausura do rio Amazonas. Ficava, assim, derrotada a ideia que fora predominante desde 1826, segundo a qual os estrangeiros e seus capitais deveriam ficar afastados do Amazonas, sob pena da quebra da integridade territorial do Império brasileiro. Essa decisão foi fundamental poucos anos depois, quando, em 1871, Irineu Evangelista de Souza recebeu do governo imperial autorização para repassar sua Companhia de Navegação e Comércio do Rio Amazonas a empresários ingleses, que formariam a The Amazon Steamship Company (Caldeira, 1995, p. 481-482). Essa nova companhia, formada quase exclusivamente com capital estrangeiro, manteria o virtual monopólio no campo da navegação a vapor na região amazônica até sua liquidação, em 1911, quando foi substituída pela Amazon River (Santos, 1980, p. 58).

Restavam, entretanto, outras decisões a ser tomadas. Juntamente com o projeto de abertura do rio Amazonas, outro foi apresentado, com o apoio dos deputados pelo Grão-Pará e pelo Amazonas. Segundo esse documento, constante de apenas dois artigos, o governo imperial ficaria autorizado a subvencionar com as quantias que julgasse conveniente as navegações a vapor dos rios Negro, Madeira e Tapajós, afluentes do Amazonas. Imediatamente recebeu a oposição de Tavares Bastos, José Liberato Barroso, entre outros. Segundo esses deputados, a criação de mais uma subvenção governamental - a exemplo do que já ocorria com a Companhia de Navegação e Comércio do Rio Amazonas -, 
serviria como um obstáculo à livre navegação que se intentava introduzir na região. Deveria predominar, para eles, a ideia segundo a qual apenas a livre concorrência poderia agir eficazmente para desenvolver a região Norte do País, uma vez que os benefícios garantidos pela ação de uma única companhia subvencionada já haviam chegado ao seu limite.

Para os signatários do projeto e seus defensores, ao contrário, seria impossível que apenas a concessão da liberdade de navegação do rio Amazonas fosse capaz de estimular o surgimento de idêntica atividade em seus afluentes. Nesses termos, nas palavras de Antônio José Moreira, deputado pelo Amazonas:

Depois, senhores, acreditará por ventura alguém que a liberdade de navegação do Amazonas traga imediatamente a organização de empresas que, sem subvenção, sem coadjuvação do governo, vão navegar aquelas águas [dos afluentes deste rio]? Não decerto. (Anais da Câmara dos Deputados, sessão de 8 de abril de 1864 , p. 80 )

Os argumentos dos defensores do projeto de subvenção, portanto, eram basicamente os mesmos dos que defendiam o privilégio de exclusividade nos debates anteriores. Para eles, o estado atual do País requeria tal medida como algo necessário para o desenvolvimento da região que, sem esse auxílio, não ocorreria. Não foi possível encontrar a decisão final acerca desse objeto, mas, da ausência de continuação na discussão e da rejeição, sem debate, de uma proposta praticamente idêntica em 1866 (Anais da Câmara dos Deputados, sessão de 20 de março de 1866, p. 41), podemos deduzir que o projeto de subvenção foi rejeitado. Predominava, assim, a opinião liberal de que a abertura do rio Amazonas bastava para desenvolver o Norte do País e para inseri-lo nas rotas comerciais internacionais. A partir de agora, a tese predominante seria a de que a criação de outras subvenções na região não era uma medida desejável, da mesma forma como ocorrera com o privilégio de exclusividade, anos antes. Fechava-se, assim, mais um ciclo do processo de liberalização da navegação na região amazônica. Nesse processo, os representantes da região foram derrotados pelos deputados que consideraram mais vantajoso não onerar ainda mais os cofres públicos.

Uma vez decidido que a abertura da navegação do rio Amazonas seria realizada, atraindo, assim, capitais externos para a região, e que, para garantir o sucesso dessa medida, seria necessário obstar a criação de subvenções pecuniárias a ser pagas pelo governo imperial, restava finalmente decidir a forma pela qual os estrangeiros adquiririam o direito de entrar com seus barcos 
na região amazônica. Pelo projeto original de abertura, apenas os países que celebrassem previamente tratados com essa finalidade com o governo imperial teriam direito a navegar as águas do rio Amazonas. Segundo Franco de Almeida, um dos signatários desse projeto, a intenção desse dispositivo era garantir para o Império a possibilidade de cobrar reciprocidade dos demais países pelo benefício representado pela abertura do rio Amazonas (Anais da Câmara dos Deputados, sessão de 9 de junho de 1864, p. 90).

Rapidamente essa ideia passou a receber acerbas críticas. Para Fábio Alexandrino Carvalho Reis, deputado pelo Maranhão, abrir o Amazonas mediante a assinatura de tratados bilaterais com todos os países que se interessassem por essa atividade não seria mais do que procrastinar a abertura total, que era a que interessava à Nação. Para ele, apenas a assinatura de tratados com os demais países ribeirinhos era necessária, como forma de incentivá-los a negociar com o Império questões de interesse, como os limites, por exemplo (Anais da Câmara dos Deputados, sessão de 8 de junho de 1864, p. 73-75). Neste sentido, o deputado apresentou um projeto substitutivo que consistia em impor, por vias legislativas, condições para a abertura do rio Amazonas, de forma a permitir ao governo uma possibilidade de resistir melhor à pressão diplomática estrangeira, principalmente dos países mais fortes (Anais da Câmara dos Deputados, sessão de 20 de fevereiro de 1864, p. 161-162). Essas condições iam, em sua totalidade, ao encontro do ideal de habilitar o Poder Executivo com meios eficientes de vigilância e controle sobre essa atividade. Assim, todos os barcos deveriam ficar obrigados, em primeiro lugar, a realizar seu trajeto sempre por intermédio do porto de Belém, capital da província do Grão-Pará, pois, afirmou o deputado, “do contrário não poderemos nunca exercer fiscalização nenhuma sobre tal navegação" (Anais da Câmara dos Deputados, sessão de 20 de fevereiro de 1864, p. 161).

Da mesma forma, todos os barcos que passassem pelo Brasil em direção aos países limítrofes e que voltassem em direção ao oceano deveriam obrigatoriamente passar por portos habilitados em território imperial, sendo essa uma condição sine qua non para a abertura. Finalmente, a liberdade de navegação deveria ser limitada, inicialmente, aos países ribeirinhos com os quais o Império já possuísse tratados e convenções, no caso o Peru e a Venezuela. Com isso, pressionavam-se os outros vizinhos a celebrar contratos nos mesmos termos, favorecendo, assim, a posição brasileira nas discussões sobre temas de interesse para o País, como as questões de limites e extradi- 
ção de escravos fugidos, ambos inseridos nos tratados já existentes. Posteriormente, essa ideia foi alterada para a obrigatoriedade de celebração de convenções com os países ribeirinhos, ficando os demais dispensados dessa formalidade para obterem o direito expresso pela abertura. Desta forma, para Carvalho Reis, a questão da navegação do Amazonas, assim como para os signatários do projeto original de abertura, deveria tornar-se uma importante moeda de troca nas questões internacionais de interesse para o Império, já que esse estaria espontaneamente abrindo mão de uma prerrogativa garantida pela sua soberania em favor dos interesses do comércio mundial e, portanto, da humanidade.

Para Franco de Almeida, a proposta de Carvalho Reis não poderia ser adotada em hipótese alguma, em nome dos ideais de justiça que deveriam guiar todas as políticas assumidas pelo governo imperial:

Senhores, parece-me que o nobre deputado foi sumamente injusto com os ribeirinhos. Até aqui en estava persuadido de que os ribeirinhos tinham mais direitos que os países que não o eram; estava persuadido de que as repúblicas ribeirinhas do Amazonas ou de seus afluentes tinham mais direito a navegá-lo do que a França, a Inglaterra e os Estados Unidos; mas o nobre deputado sustentando que se abra a navegação e comércio do Amazonas, inde- pendente de convenções e tratados, a todas as bandeiras estrangeiras, veio tornar de pior condição os Estados ribeirinhos, quando disse que para eles se precisa de convenções. (Anais da Câmara dos Deputados, sessão de 9 de junho de 1864, p. 91)

A proposta defendida por Franco de Almeida acabaria sendo aprovada, mas não sem antes sofrer novas críticas. A principal argumentação utilizada nesse sentido pode ser resumida na seguinte fala do deputado por Minas Gerais, Martinho Álvares da Silva Campos. Vejamos:

$V$ em a ser essa reciprocidade nada mais que o esconderijo derradeiro desse velho ciúme que isolava e seqüestrava o Brasil do resto do mundo, e monopolizava o seu comércio em proveito da dominação colonial, a última forma de um sistema protetor pouco inteligente, que não ousa mais apresentar-se sem disfarce, porque um país vastíssimo e pobre de população e de capitais como o nosso, um pais em que infeliz. mente somos obrigados a confessar que o espirito de empresa, que não pode viver nem elevar-se sem auxílio do espirito de associação, ou não existe, ou tem sido infeliz na maior parte de seus ensaios; um país nestas condições o que pode esperar do direito de reciprocidade? Da preconizada reciprocidade, tão inculcada pelo meu honrado amigo, que partido podemos tirar? (Anais da Câmara dos Deputados, sessão de 10 de junho de 1864, p. 107) 
O projeto que previa a abertura do rio Amazonas mediante assinatura prévia de convenções nesse sentido foi aprovado pela maioria dos deputados em 16 de junho de 1864, e, já no dia 18, entrou em discussão no Senado. Na casa vitalícia, novamente a ideia sofreu forte oposição, principalmente de José Maria da Silva Paranhos, visconde do Rio Branco:

Será necessário que tornemos a abertura do Amaronas dependente, para as potências não ribeirinhas, de tratados com essas potências? Se elas não se prestarem à celebração desse acordo? Se não convier ao Império prender-se por estipulações dessa natureza a respeito de uma medida em que ele deve ter exclusiva soberania? $O$ projeto não deixa arbitrio ao governo, impõe-lhe o dever de não franquear a navegação e comércio do Amazonas às nações não ribeirinhas, se antes não celebrar tratados para esse fim com essas potências. (Anais do Senado, sessão de 27 de junho de 1864, p. 166)

Como não queria se opor frontalmente ao projeto em discussão, o senador apresentou um requerimento no qual era solicitado o envio do texto a duas comissões do Senado, a da Fazenda e a da Diplomacia, para que elas pudessem, conjuntamente, chegar a um consenso acerca do melhor a ser feito com relação ao tema.
Sem qualquer discussão, o requerimento foi prontamente aprovado pela maioria dos senadores, e a discussão ficou adiada até que as comissões apresentassem seu parecer (Anais do Senado, sessão de 27 de junho de 1864, p. 167). Esses documentos, entretanto, nunca foram emitidos, como foi lembrado na reunião do Conselho de Estado que aprovou a abertura do Amazonas, em 3 de dezembro de 1866 (Rodrigues, 1978, p. 120). Embora não tenha sido oficializada, a posição do Parlamento predominantemente favorável à abertura do rio Amazonas estava claramente definida. Isso facilitou a tomada de posição do Conselho de Estado na reunião acima citada, quando a abertura foi unanimemente aprovada, e decidiu-se que a melhor estratégia para adotá-la seria a formulação de um decreto, em vez da celebração de acordos bilaterais, como preferiu a Câmara dos Deputados.

Nesse sentido, o Decreto n. 3.749, de 7 de dezembro de 1866, culminou um longo processo decisório que se iniciou em 1826 e que sempre teve como preocupação central a incorporação da região amazônica ao conjunto do Império da forma mais vantajosa possível, através da adoção de medidas que garantissem seu desenvolvimento econômico. O Decreto n. 3.920, de 31 de julho de 1867, regulamentou a forma pela qual a navegação internacional 
deveria ser realizada na região amazônica, e, em 7 de setembro de 1867, deu-se a solenidade oficial de abertura, em um ritual repleto de significados ocorrido no exato ponto em que o Amazonas encontra-se com o oceano Atlântico. ${ }^{10}$

A população do território abrangido pelo decreto de abertura não ficou impassível ao acontecimento. Desta forma, nos meios de comunicação de Belém, surgiram, nas semanas anteriores e posteriores à solenidade de abertura, vários textos de louvor ao evento:

Nações do mundo, várias
Entrae, sede bem vindas,
As plagas amazônicas
Imensas, ricas, lindas!
Missão audaz e bélica
Não é que aqui vos traz...
Vindes saudar o Império,
Saudar vindes a paz!
Com o vento brincam os rutilos,
Bizarros pavilhões,
As variadas flâmulas
De inúmeras naçoes!
Recebe-vos com júbilo
O povo brasileiro:
Na guerra altivo, indômito,
Na paz hospitaleiro!
Bem vindos sejam os hóspedes!
O rio é franco, entrae!
O collossal mystério
Abriu-se, admirae! (Serra, 1867)

Terminava assim, de forma festiva, um longo processo decisório em que esteve em jogo a soberania nacional e a integração ao Império de uma região repleta de potencialidades.

\section{Conclusão}

A incorporação da região amazônica ao conjunto do Estado nacional brasileiro não se resolve com a adesão das elites do Grão-Pará à independência em 1823. Essa escolha em momento algum pode ser entendida como definitiva, e, durante todo o século XIX, os responsáveis pela administração imperial tiveram de formular, mediante debate, políticas capazes de desenvolver economicamente todo o Norte do País, garantindo, assim, sua plena soberania sobre aquele território. $\mathrm{O}$ processo decisório que decorreu dessa necessidade não foi simples nem uniforme. Ao longo de todo o período que vai de 1826, data da primeira tentativa de introdução da navegação a vapor no rio Amazonas, até 1871, quando a companhia fundada por Irineu Evangelista de Souza em 1852 passa definitivamente para o capital inglês, várias ideias foram formuladas, adotadas e posteriormente abandonadas, em um processo decisório que caminhou pari passu com a consolidação do Estado nacional brasileiro.
10 Ofício da presidência da provincial do Pará sobre a abertura do rio Amazonas e outros, 18 de setembro de 1867. Relatório apresentado à Assembleia Geral Legislativa na segunda sessão da décima terceira legislatura pelo ministro e secretário de Estado dos negócios da Agricultura, Comércio e Obras Públicas, Manoel Pinto de Souza Dantas, 1868, p. 1-2. 
Nesse sentido, a aversão à presença de capitais estrangeiros na atividade de navegação, fortemente presente em todas as discussões da primeira metade do século, e responsável pelo malogro de várias tentativas de introdução de linhas regulares de vapores nos rios amazônicos, caiu no debate parlamentar de 1864, não sem resistência de alguns deputados. O temor de perder a posse sobre tão grande território cedeu ante a necessidade de consolidar e aumentar os ganhos conseguidos após anos de navegação subvencionada pelos cofres gerais. A ideia da existência de um privilégio de exclusividade, nunca aceito plenamente ao longo de todos os debates, acabou surgindo na prática durante o período de quatorze anos, que vai desde o início das atividades da Companhia de Navegação e Comércio do Rio Amazonas, em 1853, até a fundação de suas primeiras concorrentes nacionais, em meados da década de 1860. Posteriormente, voltaria a se fazer presente com a Amazon Steamship Company, de capital inglês, responsável única pelas linhas amazônicas desde a década de 1870 até a segunda década do século XX. Na prática, a livre concorrência, tão defendida por vários deputados e senadores ao longo de todas as discussões, não foi capaz de se estabelecer eficazmente na região amazônica durante todo o Império, o que não impediu, entre- tanto, que, graças ao boom da borracha, o comércio internacional amazônico atingisse patamares nunca antes alcançados a partir da década de 1870.

Ainda nessa linha, a subvenção governamental, defendida como a forma mais eficaz de incentivar a introdução da navegação a vapor na região amazônica, na década de 1840, acabou sendo rejeitada pouco mais de vinte anos depois como um obstáculo sério ao processo de abertura do rio Amazonas aprovado em 1864. Todavia continuou servindo como um dos pilares financeiros das principais empresas que realizaram essa atividade ao longo de praticamente todo o período imperial, uma vez que os subsídios já aprovados pelo Parlamento continuaram sendo pagos para as companhias que os receberam e para as que herdaram posteriormente suas atividades.

O que é perceptível durante todo esse processo decisório é uma tendência à liberalização nos discursos à medida que $\mathrm{O}$ tempo corria, e o comércio amazônico passava a apresentar cifras satisfatórias. Contudo, se isso pode ser verificado no campo teórico dos debates parlamentares e das medidas governamentais, na prática cotidiana nem sempre os resultados alcançados foram os esperados. Quando a companhia do futuro barão de Mauá iniciou suas atividades em 1853, constava do rol de vanta- 
gens oferecidos pelo governo um privilégio de exclusividade, e de suas obrigações a fundação de colônias nas margens do rio Amazonas. O primeiro item caiu na reforma contratual de 1854, e o segundo, na de 1857. A concorrência que deveria resultar do final da exclusividade não ocorreria antes de 1866 , e a fundação de prósperas colônias em uma das regiões mais ricas do Império, após algumas tentativas de Mauá, não alcançaria os resultados desejados. Um processo cheio de percalços, idas e vindas, debates e decisões. A história do desenvolvimento econômico da Amazônia no século XIX sofreu duros revezes e correu algumas vezes o risco de ser abortado precocemente. Entretanto, acabou resultando na incorporação de um terço do atual território brasileiro ao conjunto do País, e na consolidação do processo de formação do Estado nacional. Isso não significa, contudo, que todos os problemas da região foram resolvidos durante o regime imperial. Significa apenas que, após as políticas adotadas nessa época, a região amazônica pode sentir-se, finalmente, parte da comunidade brasileira. 


\section{Referências bibliográficas}

ANAIS da Câmara dos Deputados. Disponível em: $<$ http://www2.camara.gov.br/ publicacoes $>$. Acesso em: 16 jul. 2009 .

ANAIS do Senado. Disponível em: <http://www.senado.gov.br/ sf/publicacoes/anais/asp/PQ Pe squisar.asp $>$. Acesso em: 16 jul. 2009.

DISCURSO com que o presidente da província do Pará fez a abertura da $1^{\text {a }}$ Sessão da Assembleia Provincial no dia 2 de março de 1838. Disponível em: $<$ http://www.crl.edu/content/br azil/para.htm>. Acesso em: 16 jul. 2009

DISCURSO recitado pelo Exmo. Sr. Doutor João Antônio de Miranda, presidente da província do Pará, na abertura da Assembleia Legislativa Provincial, no dia 15 de agosto de 1840 . Disponível em: <http:/ / www.crl.edu/content/brazil/ para.htm>. Acesso em: 16 jul. 2009.

CALDEIRA, Jorge. Maná: empresário do Império. São Paulo: Companhia das Letras, 1995.
DOLHNI OFF, Miriam. O pacto imperial - origens do federalismo no Brasil. São Paulo: Globo, 2005.

GREG RIO, Vitor Marcos. Uma face de Jano: a navegação do rio Amazonas e a formação do Estado brasileiro (1838-1867). 2008. Dissertação (Mestrado em História Social) - Faculdade de Filosofia, Letras e Ciências Humanas, Universidade de São Paulo, São Paulo, 2008.

MACHADO, André Roberto de Arruda. A quebra da mola real das sociedades - a crise política do antigo regime português na província do Grão-Pará (1821-1825). 2006. Tese (Doutorado em História Social) FFLCH, Universidade de São Paulo, São Paulo, 2006.

MAURY, F. O Amazonas e as costa. atlanticas da América Meridional. Rio de Janeiro: Typographia de M. Barreto, 1853.

MEDEIROS, Fernando Sabóia de. A liberdade de navegação do Amazonas (relações entre o Império e os Estados Unidos da América). Rio de Janeiro: Companhia Editora Nacional, 1938.
MEDEIROS, Vera B. Alarcón. Incompreensivel Colosso - a

Amazônia no início do Segundo Reinado (1840-1850). 2006. Tese (Doutorado em Ciências Humanas e Sociais) - Faculdade de Geografia e História,

Universidade de Barcelona, Barcelona, 2006.

REIS, Artur César Ferreira. A Amazônia e a cobiça internacional. Rio de Janeiro: Companhia Editora Americana, 1982.

RELAT RIO do Ministério do Império, 14 de maio de 1855

Disponível em:

<http://brazil.crl.edu/bsd/bsd/h artness/imperio.html>. Acesso em: 16 jul. 2009.

RELAT RIO do Ministério do Império, 6 de maio de 1858.

Disponível em: <http:/ / brazil.crl.edu/bsd/bsd/hartness/i mperio.html>. Acesso em 16 jul. 2009.

RELAT RIO do Ministério da Agricultura, Comércio e Obras Públicas, 10 de janeiro de 1864. Disponível em: <http:// brazil.crl.edu/bsd/bsd/hartness / agricultura.html>. Acesso em: 16 jul. 2009.
RELAT RIO apresentado à Assembleia Geral Legislativa na segunda sessão da décima terceira legislatura pelo ministro e secretário de Estado dos negócios da Agricultura, Comércio e Obras Públicas, Manoel Pinto de Souza Dantas, 1868. Disponível em: <http://brazil.crl.edu/bsd/bsd/h artness/agricultura.html $>$. Acesso em: 16 jul. 2009.

RELAT RIO apresentado à Assembleia Legislativa Provincial na primeira sessão da $17^{\mathrm{a}}$ legislatura, pelo $4^{\circ}$ vice-presidente, doutor Abel Graça, 1870. Disponível em: $<$ http://www.crl.edu/content/br azil/para.htm>. Acesso em: 16 jul. 2009.

RODRIGUES, José Honório (Org.). Atas do Conselho de Estado, Ata de de dezembro de 1866. Brasília: Senado Federal, 1978, vol. VI, p. 120.

SAMPAIO, Marcos Guedes Vaz. Navegação a vapor na Babia oitocentista: tentativa de integração territorial e desenvolvimento regional. Revista de Economia Política e História Econômica, n. 14, p. 5-45, ago. 2008. 
SANTOS, Roberto Araújo de Oliveira. História econômica da Amazônia (1800-1920). São Paulo:

T. A. Queiroz, 1980.

SERRA, Joaquim. A abertura do Amazonas. Publicado no jornal Diário do Gram-Pará, edição de 7 de setembro de 1867 , primeira página. Material coletado em pesquisa na sessão de microfilmes do Centur, em Belém (Pará).

\footnotetext{
: Pesquisa financiada pela

- Fundaça de Amparo à

- Pesquisa do Estado de São

: Paulo (Fapesp)

E-mail do autor:

. vitorgregorio@usp.br

:

- Artigo recebido em em dezembro de 2008;

- aprovado em maio de 2009.
} 